\title{
Mário Guimarães Ferri: o botânico ecólogo
}

G. M. FELIPPE

$\mathrm{E}$

m 15 de junho de 1985 morreu em São Paulo o professor Mário Guimarães Ferri, um grande cientista brasileiro e um professor excepcional. Seu poder de comunicação aliava-se a um grande amor pela Botânica e a um profundo conhecimento científico: por isso era um grande mestre. Ter sido aluno do professor Ferri foi uma das grandes alegrias que a Universidade de São Paulo, através do curso de História Natural, me proporcionou. Seu incentivo, mais tarde, foi fundamental em minha carreira. Poder partilhar com o professor Ferri um bom whisky em sua casa, noite a dentro, e participar de discussōes infindáveis sobre qualquer assunto, foi um privilégio.

Ferri fez o curso superior na Faculdade de Filosofia, Ciências e Letras da Universidade de São Paulo. Obteve nessa mesma Universidade o título de doutor em Ciências em 1944 e o de livre-docente em 1951. Em 1955 tornou-se professor catedrático de Botânica na.Faculdade de Filosofia, Ciências e Letras da Universidade de São Paulo. Entre 1944 e 1945 estagiou no Boyce Thompson Institute e no California Institute of Tecbnology, graças a uma bolsa de estudos da Fundação Rockefeller. Fez um curso de Fisiologia Vegetal na Columbia University. Foi nesse período que iniciou seus trabalhos na linha dos hormônios de plantas.

Foi o primeiro colaborador do professor Felix Rawitscher, o organizador do Departamento de Botânica da Faculdade de Filosofia, Ciências e Letras da Universidade de São Paulo. Com o professor Rawitscher, o professor Ferri iniciou as pesquisas com plantas dos cerrados.

Ao deixar Rawitscher o Departamento de Botânica, foi substituído por Ferri, que permaneceu como professor catedrático até sua aposentadoria. Sob sua direção, o Departamento de Botânica ganhou prestígio, razão da procura do Departamento por estagiários brasileiros e estrangeiros. Com seu conhecimento e seu poder de comunicação iniciou em pesquisa ou transformou em pesquisadores muitos dos botânicos e ecólogos hoje conhecidos.

Quando se tornou professor catedrático a atividade principal de 
Ferri desenvolveu-se em dois campos praticamente virgens no Brasil naquela época: o dos Fitormônios e o da Ecologia Tropical.

Após seu estágio nos Estados Unidos, o professor Ferri iniciou pesquisas com hormônios vegetais no Brasil, realizando-as em grande número, e orientou trabalhos de muitos estagiários no assunto. Entre os fitormônios, especializou-se no estudo das auxinas. As auxinas foram o primeiro grupo de hormónios de plantas a ser conhecido no Ocidente (ao mesmo tempo, os japoneses descobriram um outro grupo, o das giberelinas, que só veio a ser conhecido no Ocidente após o fim da Segunda Grande Guerra). Sua descoberta deve-se ao trabalho do botânico holandês Went, com quem Ferri teve o prazer de conviver e se relacionar como amigo.

Professor Ferri publicou vários artigos sobre auxinas entre 1945 e 1951. Ocasionalmente voltou ao assunto (até 1971), colaborando ou orientando outros pesquisadores. Estudou a translocaçáo de auxinas sintéticas em plantas, como também a conversão enzimática do triptofano (que é um dos precursores das auxinas) em folhas de Spinacea oleracea (o espinafre europeu). Muitos de seus trabalhos, mais interessantes tratam da inativação do ácido indolil-3-acético (a auxina mais conhecida e a mais comum) pela luz. Em 1951 publicou em Nature um trabalho muito importante sobre a fotoinativação da auxina por substâncias fluorescentes (Photoinactivation of the plant-hormone indoleacetic acid by fluorescent substances).

Até hoje é muito utilizado em pesquisa, no Brasil e no exterior, um teste biológico para a deteç̧áo de auxinas em plantas, de autoria do professor Ferri com sua colaboradora L. V. de Camargo. É o conhecido bioteste dos pecíolos do feijão. Este bioensaio baseia-se no movimento das articulaçôes das folhas primárias do feijoeiro. De plantas jovens de feijão seccionam-se segmentos compreendendo parte dos pecíolos e caule, tendo a forma de um Y. Depois de se medir o ângulo compreendido pelos lados internos dos pecíolos, colocam-se esses segmentos nas soluçóes em que se quer verificar se há ou não uma auxina. Passado algum tempo (cerca de quatro horas) medem-se novamente os ângulos. Na ausência de auxina, o ângulo final é maior que o inicial. Na presença de auxinas o ângulo final é menor. É um bioteste de execuçăo simples, emprega material de fácil obtençáo e é específico para auxinas (isto é, não responde aos outros hormônios de crescimento de plantas). Este ensaio apareceu pela primeira vez em Influence of growth substances plants, de autoria, como já foi dito, de Ferri e Camargo. Foi publicado em 1950 nos Anais da Academia Brasileira de Ciencias. Em 1951 Ferri deu mais informaçōes sobre este teste no artigo Nuevas informaciones sobre la influencia de substancias de crescimento on el mopimiento de las 
articulaciones de las hojas primarias de Phaseolus pulgaris, publicado em Phyton.

Como presidente da Editora da Universidade de São Paulo, professor Ferri prestigiou a publicação de muitos autores brasileiros e de muitas obras de Fisiologia Vegetal. Entre esses livros há um que trata quase exclusivamente dos fitormônios, Fisiologia Vegetal 2, publicado em 1979 sob a coordenação do professor Ferri. É sem dúvida um livro bem feito e muito útil para o estudante brasileiro que pretenda se iniciar no assunto, o que demonstra sua influência continuar na formação de novos pesquisadores, não tendo sido interrompida por sua morte.

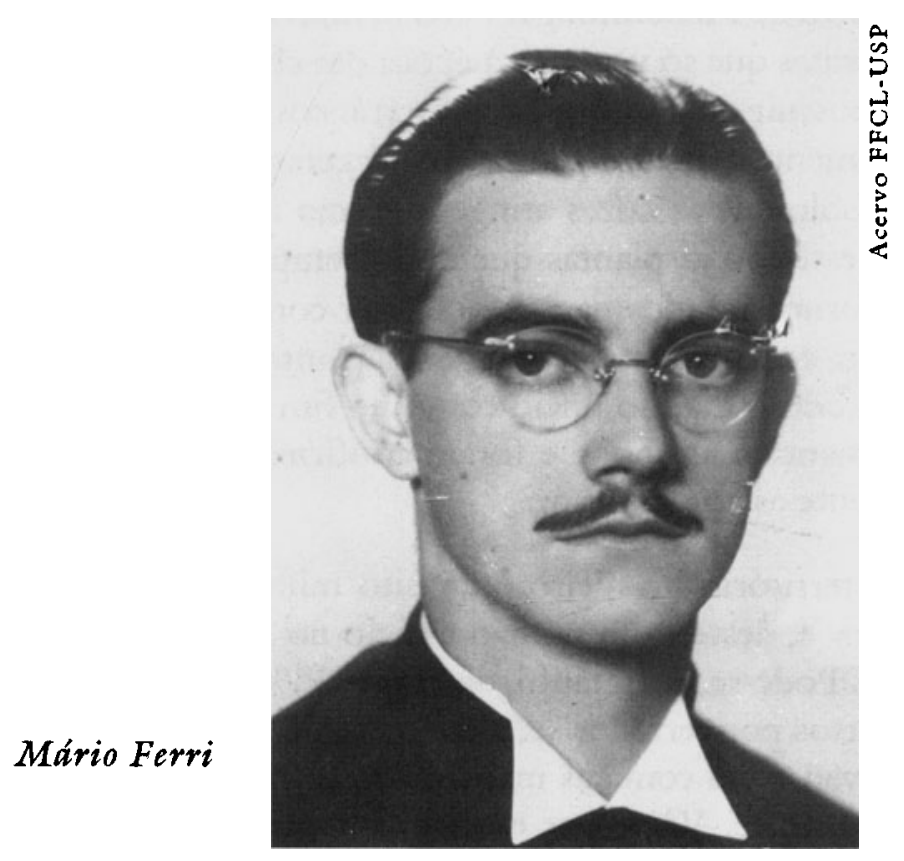

Foi uma pena que após tantos trabalhos interessantes sobre fitormônios, realizados entre 1945 e 1951, o professor Ferri tenha deixado este campo para um segundo plano, passando a dedicar-se com afinco à Ecologia. Mas, sua decisão teve muito bom senso: um pesquisador brasileiro de peso precisava dedicar-se aos trabalhos de campo com Ecologia dos cerrados, uma vez que em relação aos hormônios havia pesquisadores pelo mundo afora. E o professor Ferri tinha razão: se não fosse ele, alguém hoje poderia sequer imaginar que rumos teria tido a pesquisa de campo, principalmente dos cerrados, neste país?

Ferri, Rawitscher e Rachid publicaram nos Anais da Academia 
Brasileira de Ciencias, em 1943, o trabalho Profundidade dos solos e pegetafáo em campos cerrados do Brasil Meridional, o primeiro trabalho experimental de Ecologia feito no Brasil. Foi Rawitscher, em 1942, quem abriu o caminho para o desenvolvimento desse campo no país, com base em estudos experimentais. É óbvio, portanto, que se diga que o professor Ferri, como discípulo de Rawitscher e pelos muitos trabalhos na área, é o criador da Ecologia Experimental no Brasil.

Em 1944, professor Ferri defendeu sua tese de doutoramento Transpirafaio de plantas permanentes do cerrado, trabalho que tem mérito não só por ser pioneiro mas porque é básico em termos de transpiraçáo de plantas do cerrado e do cerrado em si. O trabalho foi realizado em Emas, perto de Pirassununga. Ferri dividiu a vegetação de Emas em três tipos: plantas que só vegetam à época das chuvas, no caso o veráo, e que podem possuir ou náo órgáos subterrâneos, os xilopódios; plantas permanentemente verdes; e plantas que vegetam até o esgotamento total da água do solo que as raízes atingem (como as gramíneas). Para elaborar sua tese estudou as plantas que estão sempre verdes, pois sáo elas que podem fornecer dados para se entender como é a economia de água na época das secas. Mostrou que essas plantas transpiram sem restriçáo durante todo o dia, no início como no fim da época seca. Suas conclusões se mantêm até hoje, e foram confirmadas por vários autores que inicialmente as contestaram.

O território brasileiro é de oito milhóes e meio de quilômetros quadrados e, destes, um milháo e meio no Brasil Central, ocupado por cerrados. Pode-se, entretanto, dizer que $25 \%$ do território do nosso país são cobertos por cerrados se, além da região ocupada no Brasil Central, forem levadas em conta as manchas de cerrado que ocorrem no sul, no leste e no norte. Vê-se por esses dados o interesse econômico que representa esse solo ocupado pela vegetação de cerrado. Em sua tese, o professor Ferri mostrou que o cerrado não é condicionado pela falta de água. Por seu interesse pelo assunto, realizou pesquisas com a vegetaçáo e formou muitos discípulos para trabalhar com problemas relacionados com os cerrados. Discípulos do professor Ferri pensam que o problema de muitas das plantas do cerrado decorre em parte da falta de nutrientes e do excesso de alumínio. Cabe agora a eles, aos seguidores de Ferri, explicar, baseando-se nessas idéias, como funciona o ecossistema cerrado.

A floresta amazônica ocupa $40 \%$ da superfície do Brasil. As caatingas cobrem $11 \%$ do território brasileiro, estendendo-se pelo Maranhão, Piauí, Ceará, Rio Grande do Norte, Paraíba, Pernambuco, Sergipe, Alagoas, Bahia e trechos de Minas Gerais. As matas costeiras 
acompanham o contorno das costas brasileiras desde o Rio Grande do Norte até o Rio Grande do Sul. Entre os tipos de vegetaçăo restantes incluem-se os manguezais e as dunas. $O$ professor Ferri esteve envolvido em pesquisa em todos esses tipos de vegetaçáo: $\mathrm{em}$ alguns deles, como as dunas, manguezais e Mata Atlântica, através de discípulos, por ele orientados na época. Ele próprio realizou trabalhos de pesquisa na Amazônia, como estudos de transpiraçăo com plantas da caatinga do Rio Negro. Em sua tese de cátedra Contribuição ao conhecimento da ecologia do cerrado e da caatinga: estudo comparativo do balanço d'água de sua vegetafão, professor Ferri comparou minuciosamente os cerrados e as caatingas, apresentando também a florística dos mesmos. Analisou, em grande número de espécies, o comportamento estomático, problemas de morfologia e anatomia das folhas. Seu interesse por problemas de Ecologia nunca arrefeceu. Foi um verdadeiro ecólogo.

Seria hoje necessário mostrar a importância da Ecologia para o desenvolvimento científico do Brasil? Quem responde é o professor Ferri: "Cremos que não. Basta atentar para o fato de que a imprensa (jornais, revistas, rádio e televisáo) dedica atualmente muito espaço ou tempo a assuntos ligados a dois temas inseparáveis, Ecologia e Poluição, para ter-se uma idéia de que este é um campo que assumiu na vida cotidiana, de algum tempo para cá, grande importância. A imprensa está de um lado a refletir essa importância e de outro a desempenhar um papel de destaque na tomada de consciência, por parte do povo e do governo, da relevância dessa Ciência na vida do homem, como de resto na de todas as outras espécies de animais, vegetais e microorganismos".

Quem conheceu o professor Ferri ou conhece seus trabalhos sabe que ele foi um ecólogo e náo um ecologista demagogo. Em suas palavras, "é muito importante distinguir o verdadeiro ecólogo do ecologista demagogo, isto é, daquele que, sem ser ecólogo, faz-se passar por tal, a fim de granjear simpatias, favores e até recursos para pesquisas supostamente ecológicas".

G. M. Felippe é pesquisador aposentado (CNPq) da seção de Fisiologia e Bioquímica de Plantas do Instituto de Botânica da Secretaria de Estado do Meio Ambiente de São Paulo.

Texto extraído de Mário Guimarñes Ferri e sua obra (Câmara Brasileira do Livro, São Paulo, 1986, p. 33-38). 